\title{
ANALISIS KINERJA SAHABAT PERPUSTAKAAN DALAM SEMUA BAGIAN DI UPT PERPUSTAKAAN UNIVERSITAS NEGERI PADANG
}

\author{
Rahmatul Ikhsan \\ Universitas Negeri Padang, Padang, Indonesia \\ email: tesafitri88@gmail.com
}

Naskah diterima: 30 Desember 2019; direvisi: 20 Januari 2020; disetujui: 28 Januari 2020

\begin{abstract}
Abstrak
Penelitian ini membahas Analisis Kinerja Sahabat Perpustakaan Dalam Semua Bagian Di Perpustakaan Universitas Negeri Padang. Tujuan dari penelitian ini adalah untuk membahas apakah kinerja sahabat perpustakaan bisa mambantu perpustakaan dalam keberlangsungan fungsi dan tujuannya sebagai sumber informasi, dan layanan bagi pemustaka. Metode yang digunakan adalah metode kualitatif dengan pendekatan studi kasus. Data dikumpulkan melalui wawancara dan observasi. Informan dalam penelitian ini adalah pustakawan, pemustaka dan sahabat perpustakaan di perpustakaan Universitas Negeri Padang. Hasil dari penelitian ini adalah sahabat perpustakaan sangat membantu perpustakaan dalam melayani kebututuhan pengguna dan membantu perpustakaan dalam meningkatkan kinerja pepustakaan dalam semua bagian yang ada, mulai dari pengadaan, pengolahan, penjilidan, tata usaha, shelving dan bagian sirkulasi. Kendala yang dihadapai sahabat perpustakaan adalah kurangnya pengetahuan sahabat perpustakaan tentang klasifikasi sehingga sulit untuk menyusun buku pada rak yang sudah ditentukan, kendala lain yang ditemukan adalah banyaknya terjadi kesalahan yang dilakukan sahabat perpustakaan dalam labeling buku, ini terjadi karena kurangnya bimbingan dari pustakwan.
\end{abstract}

Kata kunci: sahabat, perpustakaan, shelving

\begin{abstract}
This study discusses the Analysis of the Performance of Library Friends in All Sections in the State University of Padang Library. The purpose of this study is to discuss whether the performance of library friends can help the library in the continuity of its functions and objectives as a source of information, and services for users. The method used is a qualitative method with a case study approach. Data collected through interviews and observations. The informants in this study were librarians, librarians, and library friends at the Padang State University library. The results of this study are library friends very helpful to the library in serving the needs of users and help the library in improving library performance in all parts, ranging from procurement, processing, binding, administration, shelving and circulation. The obstacle faced by library friends is the lack of knowledge of library friends about classification making it difficult to arrange books on a predetermined shelf, another obstacle found is that there are many mistakes made by library friends in labeling books, this is due to lack of guidance from librarians.
\end{abstract}

Keyword: friends, library, shelving 


\section{PENDAHULUAN}

Sahabat mempunyai makna dan peran yang sangat penting dalam kehidupan seseorang. Kepada sahabatlah seseorang bisa berbagi kesedihan dan kebahagian karena sahabat siap memberikan dukungan, bantuan dan solusi jika diperlukan. Sahabat berlaku bagi siapa saja baik individu maupun institusi, tidak terkecuali sebuah perpustakaan. Perpustakaan yang berdiri dengan gagahnya koleksinya yang banyak dan lengkap tidak akan berjalan lancar jika hanya mengandalkan pustakawan, perpustakaan membutuhkan sahabat yang siap membantu dalam mendukung keberlangsungan fungsi dari perpustakaan tersebut. Sahabat

perpustakaan atau "Library Friends" sudah menjadi wadah atau perkumpulan orang-orang yang peduli terhadap perpustakaan. Anggota yang terlibat dalam sahabat perpustakaan adalah orang-orang yang memang sangat peduli akan keberlangsungan fungsi perpustakaan. Di Indonesia sendiri sahabat perpustakaan sudah ada beberapa yang menerapkan di beberapa perpustakaan, seperti Perpustakaan Perguruan Tinggi, yang dimana kita tahu bahwa perpustakaan perguruan tinggi salah satu perpustakaan yang pemustakanya tergolong ramai pemustaka yang sebagian besar dari kalangan mahasiswa untuk mencari literatur yang dihutuhkan. Akibat banyaknya pemustaka yang membutuhkan literatur di perpustakaan perguruan tinggi, maka disanalah peran dari sahabat perpustakaan yang siap membantu para pemustaka untuk menemukan literatur yang dibutuhkan. (Dede Hani R, 2014)

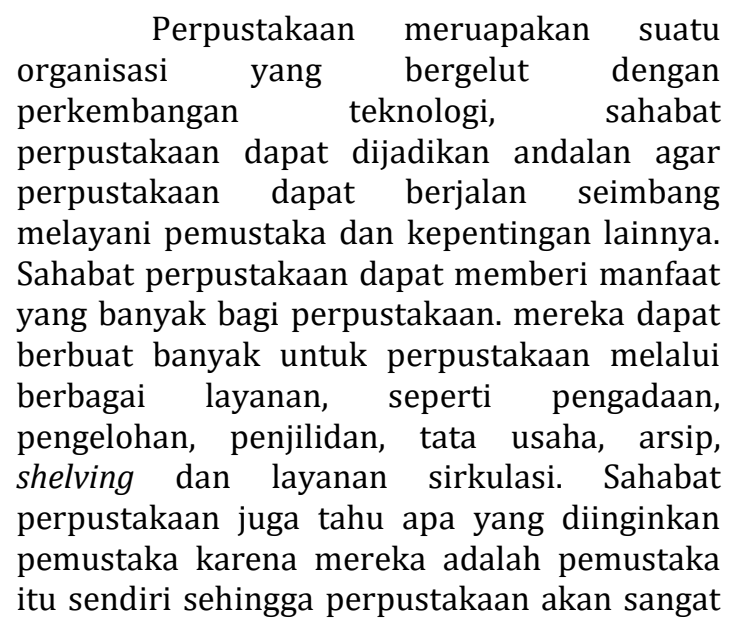

terbantu untuk memenuhi dan memperbaiki kekurangan yang ada. Sahabat perpustakan juga merupakan pendukung terbesar untuk meningkatkan pelayanan yang lebih baik lagi. Sahabat perpustakaan merupakan orang-orang dibalik layar yang senantiasa ada untuk perpustakaan. Mereka ada dibelakang untuk memantau kegiatan perpustakaan dan menyakinkan bahwa perpustakaan semakin kuat dari hari ke hari, menjadi penyedia informasi dengan melayani para pencari informasi dengan baik. (Rosinar, 2014).

Dalam hal ini peneliti akan menganalisis bagaimana kinerja sahabat perpustakaan di salah satu perpustakaan perguruan tinggi yaitu Perpustakaan Universitas Negeri Padang. Mulai dari sejarah adanya sahabat perpustakaan, manfaat sahabat perpustakaan, kendala dan solusi yang dihadapi.

Analisis bisa diartikan sebagai kajian yang dilaksanakan terhadap sebuah bahasa guna meneliti struktur bahasa yang mendalam. Sedangkan pada kegiatan laboratarium untuk memeriksa suatu zat atau cuplikan. Sedangkan dalam kamus besar ekonomi analisis yaitu melakukan evaluasi terhadap ayat-ayat yang berkaitan dengan akuntansi dan alasan-alasan yang memungkinkan tentang perbedaan yang muncul. (Salamah, 2015). Menurut Komaruddin dalam jurnal Ummu Salamah (2015: 196) , analisis adalah kegiatan berfikir untuk menguraikan suatu keseluruhan menjadi komponen, sehingga dapat mengenal tandatanda komponen, hubungannya satu sama lain dan fungsi masing-masing dalam satu keseluruhan yang terpadu.

Jadi analisis adalah suatu proses dalam mengkaji suatu hal tentang bagaimanakah kinerja dari obyek yang diteliti berdasarkan fakta dan data yang ada.

Sahabat perpustakaan atau yang dikenal dengan "Library Friends" meruapakan kumpulan orang-orang yang peduli terhadap perpustakaan, layakanya seorang sahabat yang membantu seseorang dalam menghadapi semua kesulitan yang dihadapi dan menemani seseorang dalam setiap keadaan. Sahabat perpustakaan adalah orang-orang yang suka 
rela membantu meningkatkan kinerja perpustkaan menjadi lebih baik tanpa mengharapkan imbalan atau gaji apapun.

Sahabat perpustakaan juga merupakan suatu organisasi yang didirikan oleh-oleh orang-orang yang memutuskan untuk berkolaborasi dengan perpustakaan. dengan bekerja sesuai dengan acuan yang telah dibuat dan disepakati bersama antara sahabat perpustakaan dan pihak yang terkait, semua penopang keberlangsungan fungsi layanan perpustakaan akan berjalan dengan baik dan sahabat perpustakaan akan selalu berada di jalur yang semestinya. (Rosinar, 2014).

Perpustakaan merupakan sumber informasi yang berbentuk bahan pustaka baik yang tercetak maupun non cetak, untuk itu perpustakaan dituntut untuk selalu bisa memenuhi dan melayani kebutuhan dari pemustakanya. Untuk mendukung jalannya perpustakaan sebagai sumber informasi, dibutuhkannya bagian-bagian yang mempunyai unit kerja yang berbeda agar pekerjaan di perpustakaan tidak bertumpu pada satu bagian saja. Pada umumnya perpustakaan yang memeliki banyak bagian adalah perpustakaan besar seperti perpustakaan umum, perpustakaan nasional dan perpustakaan perguruan tinggi. Berikut bagian-bagian yang mendukung kinerja di Perpustakaan Universitas Negeri Padang.

a) Bagian Pengadaan

Bagian Pengadaan di perpustakaan Universitas Negeri Padang terletak di lantai empat gedung perpustakaan. Bagian pengadaan berfungsi sebagai salah satu bagian yang mendukung pengembangan koleksi. Tugas utama dari bagian ini adalah bertanggungjawab dalam hal pengadaan bahan pustaka. Proses pengadaan dimulai dari, pertama melakukan survey dan mengirimkan surat kepada masing masing-masing fakultas untuk mengetahui bahan pustaka apa yang dibutuhkan oleh mahasiswa. Kedua, setelah mendapatkan informasi bahan pustaka yang diadakan, lalu dibuatkan list-list judul bahan pustaka dan mengirimkan daftar judul tersebut kepada pihak yang bertanggungjawab terhadap perpustakaan tersebut. Ketiga, setelah bahan pustaka itu dibeli atau didapatkan langkah selanjutnya adalah memberi stempel dan membuat inventaris dari bahan pustaka tersebut. Bahan pustaka juga bisa didapatkan melalui hadiah, hibah, sumbangan dan tukar-menukar antar perpustakaan. Keempat, selanjutnya bahan pustaka tersebut dikirmkan ke bagian pengolahan. Selain dari itu fungsi bagian pengadaan lainnya adalah tempat mendaftarkan karya ilmiah mahasiswa untuk dijadikan koleksi agar berguna sebagai referensi bagi pemustaka yang membutuhkan, contohnya tugas akhir, skripsi, tesis dan disertasi. Bagian ini dikelola oleh tiga orang pustakwan.

b) Bagian Pengolahan

Bagian pengolahan di perpustakaan Universitas Negeri Padang terletak di lantai empat gedung perpustakaan sebelah bagian pengadaan. Bagian pengolahan adalah bagian yang bertanggungjawab dalam membuat klasifikasi bahan, membuat label bahan, dan membuat katalog bahan pustaka. Pada bagian pengeolahan di perpustakaan Univeristas Negeri Padang terdiri dari tiga ruangan yaitu ruangan klasifikasi, ruangan labeling, dan raungan katalog. Rungan klasifikasi adalah ruangan yang bertugas dalam membuat klasifikasi dari bahan pustaka. Adapun ruangan labeling adalah ruangan yang bertugas dalam membuat dan menempelkan label pada bahan pustaka. Dan ruangan katalog adalah rungan yang bertugas dalam membuat kalatog bahan pustaka yang nantinya akan di upload ke sistem informasi perpustakaan $(O P A C)$. Ketiga rungan di perpustakaan tersebut dikelola oleh tiga orang pustakawan. Pustakawan di bagian pengolahan harus benar-benar paham tentang subjek dan klasifikasi bahan pustaka.

c) Bagian Penjilidan

Bagian penjilidan di perpustakaan Universitas Negeri Padang terletak di lantai empat gedung perpustakaan. Bagian penjilidan adalah bagian yang bertanggungjawab dalam menjilid bahan pustaka baik yang baru maupun bahan 
pustaka yang akan di perbaiki. Bagian ini dikelola oleh dua orang pustakawan.

d) Tata Usaha

Tata usaha di perpustakaan Universitas Negeri Padang terletak di lantai empat gedung perpustakaan. Tata usaha adalah salah satu bagian di perpustakaan yang bertugas dalam hal surat-menyurat dan mengantarkan surat kepada tujuannya. Selain itu tata usaha juga bertugas mencatat bahan pustaka yang baru sebagai bukti yang sewaktu-waktu dibutuhkan sebelum dikirim ke bagian pengadaan. Bagian ini dikelola oleh satu orang pustakwan.

e) Referensi

Bagian referensi di perpustakaan Universitas Negeri Padang terletak di lantai tiga gedung perpustakaan. Bagian referensi merupakan bagian menyediakan koleksi berupa referensi seperti kamus, ensiklopedia, prosiding, bibliografi, dan sarana referensi lainnnya. Bagian ini dikelola oleh satu orang pustakawan.

f) Bagian Digital

Bagian digital atau yang dikenal dengan perpustakaan digital di perpustakaan Universitas Negeri Padang terletak di lantai tiga gedung perpustakaan. bagian digital adalah bagian di perpustakaan yang menyediakan layanan koleksi digital atau berbentuk elektronik. Koleksi di bagian ini hanya bisa diakses menggunakan komputer. Bagian ini dikelola oleh dua orang pustakawan.

g) Shelving

Shelving merupakan salah satu bagian yang paling banyak di perpustakaan, shelving itu sendiri merupakan menyusun buku pada rak yang telah ditentukan sesuai klasifikasinya. Di perpustakaan Universitas Negeri Padang terdiri dari lima bagian yaitu shelving 000-301, shelving 302-370, shelving 371-400, shelving 401-600, shelving 601-999. Masing-masing bagian shelving dikelola oleh satu orang pustakawan, tugasnya adalah menyusun buku, baik buku baru ataupun buku yang berasal dari bagian peminjaman di rak yang telah ditentukan, tugas lain adalah melayani pemustaka yang datang danm membantu dalam mencari informasi yang dibutuhkan.
Pustakawan di bagian shelving dituntut lebih paham tentang klasifikasi sehingga tidak salah dalam menyusun buku.

h) BI Corner

BI Corner merupakan sebuah layanan pembaca di perpustakaan Universitas Negeri Padang yang terletak di lantai dua gedung perpustakaan. Layanan ini merupakan sebuah kerjasama antara perpustakaan Universitas Negeri Padang dengan pihak Bank Indonesia. Koleksinya berhubungan dengan ekonomi, layanan ini hanya bisa dimanfaatkan untuk baca ditempat dan koleksinay tidak bisa dipinjam. Bagian ini dikelola oleh satu orang pustakawan.

i) Bagian Terbitan Berkala

Bagian terbitan berkala di perpustakaan Universitas Negeri Padang terletak di lantai dua gedung perpustakaan. Terbitan berkala merupakan bagian di perpustakaan yang menyediakan bahan pustaka yang diterbitkan secara periodik baik perpekan, perbulan, ataupun pertahun, seperti jurnal, majalah dan koran. Bagian ini dikelola oleh satu orang pustakawan.

j) Bagian Sirkulasi

Bagian sirkulasi di perpustakaan Universitas Negeri Padang terletak di lantai dua gedung perpustakaan. bagian sirkulasi merupakan bagian transfer informasi dari perpustakaan kepada pemustaka, atau lebihnya peredaran bahan pustaka. Bagian sirkulasi terdiri dari bagian peminjaman dan bagian pengembalian. Bagian peminjaman merupakan bagian yang bertanggungjawab dalam mengurus pemustaka dalam meminjam buku, biasanya bagian ini dikelola oleh dua orang pustakawan. Adapun bagian pengembalian merupakan bagian yang bertanggungjawab dalam mengurus pengembalian buku dari pemustaka, biasanya bagian ini juga dikelola oleh dua orang pustakawan.

Secara umum jenis-jenis perpustakaan terbagai menjadi lima yaitu, perpustakaan nasional, perpustakaan umum, perpustakaan perguruan tinggi, perpustakaan sekolah dan perpustakaan khusus. Pada artikel ini peneliti 
akan membahas tentang perpustakaan perguruan tinggi karena berhubungan dengan judul artikel yang diteliti.

Perpustakaan perguruan tinggi merupakan perpustakaan yang bertugas sebagai suatu unit pelaksana teknis, mengemban tugas mendukung tujuan lembaga induknya, yaitu memberikan layanan kepada sivitas akademika dan masyarakat pemakai di sekitarnya, yang relevan dengan program Tri Dharma Perguruan Tinggi, yaitu pendidikan dan pengajaran, penelitian dan pengabdian kepada masyarakat. Dimana pada umumnya perpustakaan perguruan tinggi merupakan Unit Pelaksana Teknis (UPT) dan secara langsung berada dibawah rektorat. Kepala Perpustakaan bertanggung jawab langsung kepada Rektor. Dalam Peraturan Pemerintah No. 30/1990 tentang Pendidikan Tinggi disebutkan bahwa perpustakaan merupakan unsur penunjang Tri Dharma Perguruan Tinggi. Sebagai jantungnya perguruan tinggi, UPT Perpustakaan harus senantiasa meningkatkan kualitas pelayanannya kepada seluruh sivitas akademika. Hal ini sesuai dengan Instruksi Presiden Nomor 1 Tahun 1995 tentang perbaikan dan Peningkatan Mutu Pelayan Aparatur Pemerintah kepada masyarakat, dan Keputusan Menteri Negara Pendayagunaan Aparatur Negara Nomor 81 Tahunn 1993 tentang Pedoman Tata Laksana Pelayanan Umum. Dengan beberapa peraturan ini, mau tidak mau perpustakaan harus berbenah dan melakukan berbagai terobosan agar dapat melakukan pelayanan yang berkualitas kepada pemustaka (Rodin, 2015).

\section{METODE}

Penelitian mengenai analisis kinerja sahabat perpustakaan dalam semua bagian di perpustakaan Universitas Negeri Padang merupakan jenis penelitian kualitatif. Menurut Sugiyono (2015: 09), penelitian kualitatif adalah penelitian yang berlandaskan pada filsafat postpositivisme, digunakan untuk meneliti pada kondisi objek yang alamiah, (sebagai lawannya eksperimen) dimana peneliti adalah sebagai intrumen kunci, teknik pengumpulan data dilakukan secara triangulasi (gabungan), analisis data bersifat induktif/kualitatif, dan hasil pnelitian kualitatif lebih menekankan makna dari pada generalisasi. Jadi, penelitian kualitatif adalah suatu penelitian yang berusaha menemukan realitas, yaitu membangun realitas sosial yang diciptakan oleh individu-individu dan memahami maknanya sehingga penelitian kualitatif biasanya sangat memperhatikan proses, peristiwa dan otentisitas.

Selanjutnya, pendekatan yang digunakan dalam penelitian ini adalah studi kasus. Pemilihan jenis studi kasus dalam penelitian ini, dikarenakan studi kasus merupakan strategi penelitian dimana menyelidiki secara cermat suatu program, peristiwa, aktivitas, proses, atau sekelompok individu (Creswell, 2013: 20). Studi kasus juga dapat memberikan kemungkinan kepada peneliti untuk memperoleh wawasan yang mendalam mengenai aspek-aspek dasar tentang perilaku manusia, karena studi ini berupaya melakukan penyelidikan secara lebih mendalam, totalitas, itensif dan utuh. Selanjutnya peneliti memilih teknik purposive untuk digunakan dalam penelitian ini. Purposive adalah teknik penentuan informan yang dilakukan dengan pertimbangan tertentu. Pemilihan informan dalam penelitian ini ditentukan berdasarkan kriteria, yaitu paling dekat dengan pemustaka, sahabat perpustakaan yang sedang bertugas di perpustakaan dan pemustaka yang ada di perpustakaan. Dari kriteria tersebut peneliti menemukan tujuh informan yang terbagi atas empat orang pustakwan, dua orang sahabat perpustakaan dan satu orang pemustaka. (Budiwirawan, 2015)

Dalam penelitian ini, peneliti melakukan wawancara dan observasi sebagai teknik pengumpulan data. Wawancara digunakan sebagai teknik pengumpulan data apabila peneliti ingin melakukan studi pendahuluan untuk menemukan permasalahan yang harus diteliti, dan juga apabila peneliti ingin ,mengetahui hal-hal dari reponden yang lebih mendalm dan jumlah repondenya sedikit/kecil. Wawancara yang dilakukan merupakan wawancara mendalam, yaitu kegiatan yang dilakukan untuk mendapatkan informasi secara langsung dengan mengajukan pertanyaan antara pewawancara dengan yang 
diwawancarai. Observasi sebagai teknik pengumpulan data mempunyai ciri yang spesifik bila dibandingkan dengan teknik yang lain, yaitu wawancara dan kuesioner. Kalau wawancara dan kuesioner selalu berkomunikasi dengan orang, maka observasi tidak terbatas pada orang, tetapi juga obyekobyek alam yang lain. (Sugiyono, 2015)

Selanjutnya dalam penelitian ini peneliti menggunakan observasi partisipan atau observasi berperan serta, peneliti terlibat dengan kegiatan sehari-hari orang yang sedang diamati atau yang digunakan sebagai sumber data penelitian. Sambil melakukan pengamatan, peneliti ikut melakukan apa yang dikerjakan oleh sumber data, dan ikut merasakan suka dukanya. Dengan observasi partisipan ini, maka data yang diperoleh akan lebih lengkap, tajam, dan sampai mengetahui pada tingkat makna dari settiap perilaku yang nampak. Dalam perpustakaan yang diteliti ini, peneliti terlibat langsung sebagai sahabat perpustakaan itu sendiri.

\section{PEMBAHASAN}

\section{Sejarah Sahabat Perpustakaan Di} Perpustakaan Universitas Negeri Padang

Sahabat perpustakaan di perpustakaan Universitas Negeri Padang baru dimulai pada bulan Februari 2019. Awalnya program sahabat perpustakaaan sudah direncanakan sejak lama oleh perpustakaan tersebut, namun baru pada tahun ini terwujud. Pustakawan bernama bapak Syafniadi awalnya mengirimkan informasi di website perpustakaan, setelah beberapa hari datanglah mahasiswa untuk menemui bapak Edi tersebut untuk mengkonfirmasi. Pak Edi mensosialisasikan tentang sahabat perpustakaan kepada mahasiswa tersebut, mulai dari peraturan, tempat kerja, dan hal lain yang berhubungan dengan kinerja sahabat perpustakaan. Jumlah sahabat perpustakaan awalnya 30 orang, yang seluruhnya adalah mahasiswa prodi Perpustakaan dan Ilmu Informasi Universitas Negeri Padang, namun baru-baru ini kuota sahabat perpustakaan ditambah sehingga sahabat perpustakaan berjumlah 37 orang yang terdiri dari prodi PII dan IPK Universitas Negeri Padang.
Sahabat perpustakaan ditempatkan pada semua layanan di perpustakaan mulai dari pengadaan sampai bagian pengembalian. Sahabat perpustakaan di ajarkan bagaimana melakukan pekerjaan ditempat mereka bekerja. Sahabat perpustakaan ini membantu pekerjaan dengan sukarela artinya mereka tidak digaji hanya saja mereka hanya dikasih konsumsi, tapi nantinya sahabat perpustakaan ini akan dikasih surat pengalaman kerja yang nantinya akan berguna untuk melamar pekerjaan. Waktu kerja mereka memeliki jadwal yang sudah ditentukan dengan beberapa pertimbangan yang ada, jelasnya sahabat perpustakaan bisa bekerja bila ada waktu luang atau bila tidak kuliah.

Berdasarkan $\begin{gathered}\text { wawancara } \\ \text { beberapa } \\ \text { sahabat } \\ \text { dilakukan dengan } \\ \text { perpustakaan mereka mengatakan } \\ \text { bahwa }\end{gathered}$
alasan mereka bergabung menjadi sahabat
perpustakaan adalah ingin menerapkan ilmu
yang didapat dalam perkuliahan yang
kebetulahan prodi mereka juga berhubungan
dengan perpustakaan. Alasan lain adalah ingin
menambah pengalaman kerja mereka, agar
nantinya pada saat mereka melakukan PKL
mereka tidak canggung lagi, artinya mereka
sudah ada bekal untuk itu.

\section{Manfaat Sahabat Perpustakaan}

Sahabat perpustakaan sangat membantu perpustakaan dalam meningkatkan layanan dan kinerja perpustakaan menjadi lebih baik, berdasarkan wawancara yang dilakukan dengan pustakwan, pemustaka dan sahabat peprustakaan, berikut beberapa manfaat sahabat perpustakaan baik bagi perpustakaan, bagi pemustaka dan bagi sahabat perpustakaan itu sendiri.

a) Dapat melayani pemustaka dengan baik.

b) Memudahkan pemustaka mencari koleksi yang dubutuhkan.

c) Mempercepat kerja perpustakaan dalam semua bidang.

d) Membuat pekerjaan pustakawan tidak terlalau berat.

e) Menambah pengalaman kerja sahabat perpustakaan.

f) Mengisi waktu luang sahabat perpustakaan. 
g) Menerapkan ilmu sahabat perpustakaan yang telah dipelajari.

h) Membuat hubungan silarurahmi antara pustakwan dengan sahabat perpustakaaan semakin dekat.

i) Menambah ilmu pengetahuan sahabat perpustakaan yang tidak ada dipelajari pada kegiatan perkuliahan.

\section{Kendala Yang Dihadapi Oleh Sahabat Perpustakaan}

Pada sebuah pekerjaan pasti tidak ada kata yang sempurna, ada kekurangan dan kesalahan yang dihadapi, begitu juga dengan sahabat perpustakaan yang hanya memiliki sedikit ilmu untuk bekerja di perpustakaan. berdasarkan wawancara yang dilakukan ada tiga kendala yang dihadapi oleh sahabat perpustakaan selama bekerja pada semua bagian perpustakaan yaitu sebagai berikiut.

a) Banyaknya terjadi kesalahan yang dilakukan sahabat perpustakaan dalam menempel label buku pada bagian pengolahan. Keselahan itu berupa penempelan label pada buku tidak sesuai dengan ketentuan yang telah ada, ini terjadi karena pustakawan kurang menjelaskan bagaimana menempel label yang seharusnya dan juga pustakwan juga kurang memperhatikan pekerjaan sahabat perpustakaan dalam menempel label pada buku, dan akhirnnya buku yang salah menjadi menumpuk sehingga harus diperbaiki lagi.

b) Banyaknya sahabat perpustakaan yang kurang paham tentang shelving. Banyak sahabat perpustakaan yang kebingunan meletakkan koleksi pada rak ini terjadi karena sahabat perpustakaan kurang memahami klasifikasi dan susunan klasifikasi pada rak kadang ada yang klasifikasinya tidak berurut. Dan pada bagian shelving inilah sahabat perpustakaan merasakan lelah karna banyaknya buku yang akan disusun di rak.

c) Kurangnya ketelitian sahabat perpustakaan dalam melakukan pekerjaan di bagian peminjaman dan pengembalian. Pada saat meng-entrikan buku pada sistem informasi perpustakaan, sahabat perpustakaan kadang salah dalam mamasukkan barcode buku yang mengakibatkan banyaknya buku yang tidak terdaftar di sistem informasi perpustakaan karena barcodenya yang salah meng-entrikan.

\section{Solusi Untuk Mengatasi Kendala Yang Dihadapi Sahabat Perpustakan}

Agar semua kendala yang dihadapi sahabat perpustakaan bisa diatasi maka diperlukan solusi untuk memecahkan kendala tersebut. Solusinya yauti pertama, pustakawan harus lebih jelas lagi dalam membimbing sahabat perpustakaan tentang pekerjaan apa yang harus dilakukan secara rinci dan sampai sahabat perpustakaan itu benar-benar paham apa yang akan dikerjakannya. Kedua, sahabat perpustakaan harus rajin bertanya kepada pustakawan jiga ragu-ragu dalam melakukan pekerjaan agar kesalahan tidak terjadi. Ketiga, sahabat perpustakaan harus meningkatkan pengetahuannya tentang klasifikasi agara mudah dalam melakukan sheving. Keempat, sahabat perpustakaan harus benar-benat meningkatkan ketelitiannya dalam melakukan pekerjaan di bagian layanan sirkulasi.

\section{SIMPULAN}

Dengan adanya sahabat perpustakaaan , kinerja perpustakaan semakin membaik artinya kualitas layanan perpustakaan yang diberikan kepada pemustaka menjadi lebih prima dan kinerja perpustakaan dalam pengembangan koleksi juga semakin membaik sejak adanya sahabat perpustakaan. Pustakawan tidak lagi memikul pekerjaan sendiri, sebaliknya sahabat perpustakaan juga dapat menerapkan ilmu dan mendapatkan pengalaman kerja yang tidak mungkin didapatkan ditempat lain, ibaratnya perpustakaan dengan sahabat perpustakaan sebagai satu kesatuan yang saling membutuhkan.

\section{DAFTAR PUSTAKA}

Budiwirawan, G. N. (2015). Analisis Pelestarian Koleksi Bahan Pustaka Teretak 
PascaBencana Banjir Di Perpustakaan Ceria, Desa Jleper, Kecematan Mijen, Kabupaten Demak Padan Tahun 2013. Jurnal Ilmu Perpustakaan.

Creswell, J. W. (2013). Research Design: Pendekatan Kualitatif, Kuantitatif dan Mixed. Yogyakarta: Pustaka Pelajar.

Dede Hani R, D. S. (2014). Teknik Pelaksanaan Program Sahabat Perpustakaan SMA Negeri 1 Gununghalu Kab. Bandung Barat. Jurnal Kajian Informasi dan Perpustakaan, 71-75.
Rodin, R. (2015). Urgensi Kualitas Pelayanan Perpustakaan Perguruan Tinggi. 11-13.

Rosinar, E. (2014). Peran Penting Friends of Library Didalam Memelihara Keberlangsungan Fungsi Perpustakaan. Jurnal Perpustakaan Universitas Pendidikan Indonesia, 80-83.

Salamah, U. (2015). Analisis Fkator Penyebab Kerusakan Bahan Pustaka di Perpustakaan SMP Negeri 4 Sunnguminasa, Gowa. Jurnal Elektronik UIN Alauddin, 196.

Sugiyono. (2015). Metode Penelitian Kuantitatif kualitatif dan $r \& d$. Bandung: Alfabeta. 